Please do not remove this page

RMIT

UNIVERSITY

\title{
Probing streets and the built environment with ambient and community sensing
}

Salim, Flora

https://researchrepository.rmit.edu.au/esploro/outputs/9921861941001341/filesAndLinks?institution=61RMIT_INST\&index=null

Salim, F. (2012). Probing streets and the built environment with ambient and community sensing. Journal of Urban Technology, 19(2), 47-67. https://doi.org/10.1080/10630732.2012.698066

Document Version: Submitted Version

Published Version: https://doi.org/10.1080/10630732.2012.698066

Repository homepage: https://researchrepository.rmit.edu.au

(c) 2012 The Society of Urban Technology

Downloaded On 2023/04/26 10:49:13 +1000

Please do not remove this page 
Thank you for downloading this document from the RMIT Research Repository.

The RMIT Research Repository is an open access database showcasing the research outputs of RMIT University researchers.

RMIT Research Repository: http://researchbank.rmit.edu.au/

\section{Citation:}

Salim, F 2012, 'Probing streets and the built environment with ambient and community sensing', Journal of Urban Technology, vol. 19, no. 2, pp. 47-67.

See this record in the RMIT Research Repository at:

http://researchbank.rmit.edu.au/view/rmit:20581

Version: Submitted Version

Copyright Statement: (c) 2012 The Society of Urban Technology

Link to Published Version:

http://dx.doi.org/10.1080/10630732.2012.698066 


\title{
Probing Streets and the Built Environment with Ambient and Community Sensing
}

\author{
Flora Dilys Salim \\ Spatial Information Architecture Laboratory (SIAL), RMIT University \\ flora.salim@rmit.edu.au \\ Postal Address: \\ GPO Box 2476 \\ Melbourne VIC 3001 \\ Australia \\ Phone: +61 39925 4572, Fax: +6139925 3460
}

\begin{abstract}
Data has become an important currency in today's world economy. Ephemeral and real-time data from Twitter, Facebook, Google, urban sensors, weather stations, and the Web contain hidden patterns of the city which are useful for informing architectural and urban design. However, often data required for informing a particular building or urban project is not available. In order to gather local and real-time data of the city, sensor devices, which are now embedded in today's urban infrastructures, buildings, vehicles, and mobile phones, have become useful tools for probing streets and the built environment. The proliferations of low-cost microcontrollers that leverage physical computing have also made sensor devices more accessible and easier to configure. The wealth of data from these sensors, if aggregated, synthesized, and analyzed, has the potential to increase our understanding of human and social behaviors in the city. This paper presents a number of projects which use ambient or community sensing to probe streets and the built environment in order to capture real-time and historical data that are pertinent to specific urban contexts. The data that was further analyzed could be used to better inform various stakeholders of the city in their decision making processes, such as to assist travelers navigating the city by providing informed choices or to help architects or planners to identify better design options in an architectural or urban design, building retrofits, or new urban intervention projects.
\end{abstract}

\section{Keywords}

urban probes, sensors, ambient sensing, community sensing, mobile technology, physical computing

\section{Introduction}

Cities and communities are emergent and holistic living systems. Analyzing data flows from our urban environment is essential to reveal hidden patterns that can lead to understand the state of the city and inform new developments, building retrofit projects, or urban planning. For architects and urban designers, designing places and spaces begins with embodiment (McCullough 2004), understood as an intrinsic yet emergent quality of interactions (McCullough 2004; Dourish 2001). In the current pervasive computing age, the boundaries between the physical and the digital have blurred (Salim et al. 2011), and the digital urban layer that embodies people and places has become as important as the physical layer of cities (Ratti and Berry 2007; Santo et al. 2010). Place-based interaction can now occur naturally as users interact with places within urban spaces on both the 
physical and the digital layers (Salim et al. 2011). There are significant lessons and experiences that can be drawn from interacting with the local real-time data from a specific urban context, location, or space while formulating strategic and critical decisions over a site.

The first challenge is to identify the right data sources and gather the required data. To extract information, knowledge, and intelligence that can aid decision making, it is essential to analyze and synthesize data in its raw state. However, the dynamic spatio-temporal information about the city and how it is emerging over time may not necessarily be easily extracted from online data sources (Salim et al. 2010). Understanding the state of a city within a particular context, such as traffic congestion or public transportation, and a particular time period, is an arduous task. Real-time and historical data from the urban environment are large, complex, and may not be all relevant. Although there is already a great deal of processed data and increasingly available data in the public domain such as through Gov2.0 initiatives - attempts from government agencies to make government data more transparent and open and government's interactions with the public more participatory and collaborative (Mergel 2010) - these data are in disaggregated forms and may not represent real-time situations. Collections of raw data from multiple sources and domains need to be cleaned in order that data aggregation and management can be applied. A major part of any urban research involving non-standardized data sources is the process of cleaning the data. This pre-processing stage, before any data analysis can be performed, can be very costly and time consuming. In addition, often the data that we need to inform a particular building or urban site project has specific data requirements, such as the pedestrian volume and flow on a particular street during a specific period of time. Such data is unlikely to be available online due to the specific nature of the project.

When social, cultural, or behavioural data of a local site or community is not available, cultural probes (Gaver, Dunne, and Pacenti 1999), which is a package of maps, postcards, and other materials useful to provoke inspirational responses, can be used as tools for gathering tacit or local knowledge. However, when traditional cultural probes are used to gather data, the responses are static and do not provide a real-time and dynamic data that can show patterns of emergence over time. In order to investigate the flux and emergence of a particular urban context, new methodological approaches to gather and represent data are required. The ubiquity of personal and mobile computing, wearable devices, sensors, and digital artefacts in our built environment, which has transformed spatial interactions in urban cities as well as the way urban data is collected, holds the potential for a more efficient approach to gather real-time and dynamic data.

This paper proposes the use of sensors as urban probes for investigating environmental, behavioural, cultural attributes of the urban environment in four case studies. Urban probes are functional artefacts, which combine the technological and social aspects of urban computing, for collecting information about the users or the use of technology in real-world setting (Paulos and Jenkins 2005). Paulos and Jenkins (2005) introduced urban probes that explore urban trash with elements of provocation to generate inspirational and playful responses. Urban probes demonstrated in (Paulos and Jenkins 2005) were used for observing urban public trash system and the response from the public or recipients of the probes for performing interventions and deriving cultural meaning of a place.

In this paper, sensors will be used as urban probes, not just for investigating cultural meanings, but also for gathering information about the natural environment which may not require any human input or public response. The purpose of the probes, aside from being tools for information gathering, is for informing architectural and urban design projects and can be used as active urban intervention tools. 


\section{Ambient and Community Sensing with Urban Probes}

The proliferation of sensors and Web 2.0 data contribute to new opportunities to extract emerging behavioral patterns of the city. Three types of existing urban sensors that can be used as probes are infrastructure sensors, vehicle sensors, and mobile devices. Ambient sensing, in this paper, refers to the use of sensors in the infrastructure, existing systems, or with DIY urban probes. Community sensing requires public participation, employing mobile phones or physical computing prototypes, to crowdsource information when probing a specific issue. This definition extends Krause et al's (2008) definition of community sensing, which is a method to share and access data from privately held sensors such as mobile devices.

Archived and real-time data from sensors embedded in the urban environment provides the potential for monitoring the current operating conditions of the city. Lessons can be drawn from existing building projects that have good energy performance ratings, demonstrate sustainable building operations, or accommodate satisfied occupants. Solar and energy analysis can be performed on the existing land use of the built environment. Residential and office buildings are now installed with smart meters which stream real-time energy use data. Coupled archived socio-economic data and data from energy simulations of the built environment, live sensor data after matching with expert domain specific knowledge can provide information that is pertinent to discovering patterns of sustainable urban living.

Inherently, the issues of transportation are closely associated with urban living. Public transport and personal motor vehicles are major contributors to greenhouse gas emissions and air pollution in urban cities. Today's vehicles and on-road infrastructures are equipped with a large number of sophisticated sensory devices which are capable of monitoring and providing data pertaining to vehicle status, real-time traffic conditions, traffic incidents, and road crashes (Salim et al. 2008). Sensors, in intelligent transportation systems, are designed and created to monitor the conditions of the vehicles, the road, and the environment in specific vicinities, such as weather information and traffic conditions. Communication and satellite navigation devices are becoming intrinsic features of the recently released vehicles. Global Positioning System (GPS) has been used widely in navigation, map creation, land surveying, and also tracking vehicle maneuvers.

Communities have also been probed using crowdsourced applications on their mobile phones. Urban commuters carry sensors embedded in their mobile devices. Mobile devices and smart phones are now equipped with GPS, accelerometers, compasses, and various other sensors. In addition, the rise of micro-blogging (Twitter), social networking (Facebook, Ning, Academia, and the like), and Web 2.0 powered with geo-tagging capabilities provides networks of emergence and convergence of spatial interactions and knowledge of and about our cities. With their mobile devices, urban commuters are able to tap into the online resources for tasks such as travel information, route planning, getting nearest points of interests, and much more. Mobile phone data can be mined to reveal hidden patterns, such as the project by Eagle et al. (2009) which employs mobile phone data to infer behavioral data of friendships.

Given the proliferation of open source microcontrollers, sensors, and actuators, new digital and electronic kits can now be designed and deployed as probes. This is particularly useful when existing sensor devices are not accessible or further customization is required. Open source electronic prototyping platform such as Arduino, which allows numerous types of sensors, actuators, and microcontrollers to be connected with any household objects, computer codes, and digital devices, have popularized the "make" or do-it-yourself (DIY) culture (Hertz 2011). The Arduino board with its family of sensors was chosen for several reasons, first was the cheap and ready availability of the device and its add-on components. Support for a wide variety of sensors, an easy-to-use development 
environment and a thriving open source Arduino community formed the other reasons. Arduino is open source and it uses a variant of the Processing IDE and a modified version of $\mathrm{C}++$ called Wiring as the embedded language.

Using the data gathered from ambient and community sensing as environmental or socio-cultural probes, these data are then further analyzed. When this information is used in early stages of architectural or urban design, this will have a great impact on the project since $80 \%$ of design decisions affecting a building project's outcomes are made in the first $20 \%$ of the project life (Crawford et al. 2004). If relevant public data exist from online data streams, social network data, or crowd-sourced mobile applications, the collected data needs to be aggregated with the online data. This pool of data may then be analyzed quantitatively and qualitatively, and visualized. Quantitative approaches may include statistical and computational data mining. The domain experts need to interpret the results of data mining into knowledge that can be visualized, such as using mashup techniques. A mashup interrelates information from various online data sources in order to present and visualize the data contextually to the user is intended for contextual information representation for a situated purpose through "ingestion, augmentation, and presentation" of online information sources (Jhingran 2006). This is useful for informing decision making processes in urban design or planning projects or performing interventions.

Using sensors as probes, individuals and communities can access and process digital data about their environment while interacting with their physical environment. Web 2.0 initiatives such as Open Street Map facilitate "crowdsourced" activities - public participation to contribute data and content to a specific application - in populating the world maps. With the availability of Pachube, a site for publishing sensor data feeds, sensing with DIY urban probes has become collective and participatory. Hence, the usage of such probes facilitates an integrated initiative of ambient and community sensing. A recent example of ambient and community sensing was the real-time radiation monitoring during Japan tsunami in March 2011 (Pachube 2011). Using Geiger counter, which was used to measure nuclear radiation, as the sensor of the probes, the data were streamed live to Pachube. A site was set up to mashup the geotagged sensor data with Google Maps to visualize the radiation across Japan. The real-time visualization showed a good indication where the radiations were at its worst.

To probe the built or natural environment using ambient or community sensing, it is essential to establish the data requirements for the specific issue that requires probing and investigate the availability of sensors. If mobile devices are going to be used, special applications or "apps" may need to be developed for specific probing purposes. If data sources from existing sensors or the sensor devices are not available, then DIY urban probes need to be made using Arduino.

\section{Case studies}

The following prototypes employ ambient or community sensing to probe the natural or built environment in Melbourne. An example of DIY urban probe for environmental probing is Ambient Light Informer, a DIY urban probe for analysing a site to inform the design of responsive louvers of a reading room in Melbourne Botanical Garden. Automated POE, the DIY urban probe, which enabled automation of Post Occupancy Evaluation (POE) survey for probing occupants' perception of comfort in a particular building. $U \& I$ Aware is a project that uses infrastructure and in-vehicle sensors for probing street intersections. In two ongoing projects, iCO2mmunity and Transafe, web and mobile applications were designed as cultural probes to gather data and improve our understanding of public perception of transport performance, sustainability, and safety. Transafe and iCO2mmunity used mobile phones to probe streets and public transportation. 


\section{1. Ambient Light Informer}

A new reading space in Melbourne Botanical Garden needs to be designed (Fig. 1). The key part of the design brief given to a Master of Architecture student in RMIT was that reading space needs to be passively designed to provide good light environment for reading.
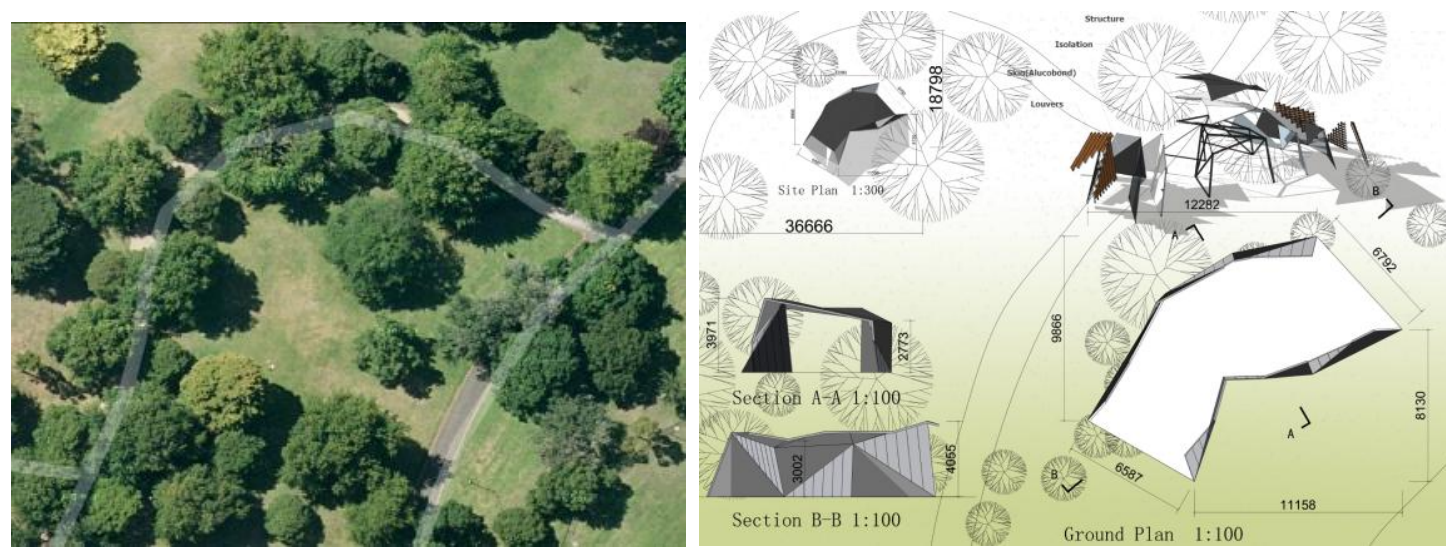

Figure 1. Left - a site chosen for the pavilion in Melbourne Botanical Garden. Right - the pavilion model.

To inform the design, instead of using the traditional approach of using light simulation and a solar path diagram in order to predict the light level at different times of day, experiments were performed with a lux reader and ambient light informer, the DIY urban probe, made of a number of light sensors connected to an Arduino (Figure 2) in the preliminary design processes. Although there can be a number of parameters in designing a comfortable reading space, such as noise, temperature, wind, and light, given the short time frame of the project, light was chosen as a design constraint of the reading space for proof of concept.

Firstly, we experimented with Rhino 3D models that are responsive to real-time ambient light data input from Arduino Light-Dependent-Resistors (LDR). Changes on the ambient light level trigger fluctuations on LDR readings, which subsequently trigger updates on the parametric models set in Rhino (Figure 2). The parametric variations in the Rhino model are scripted using RhinoScript.

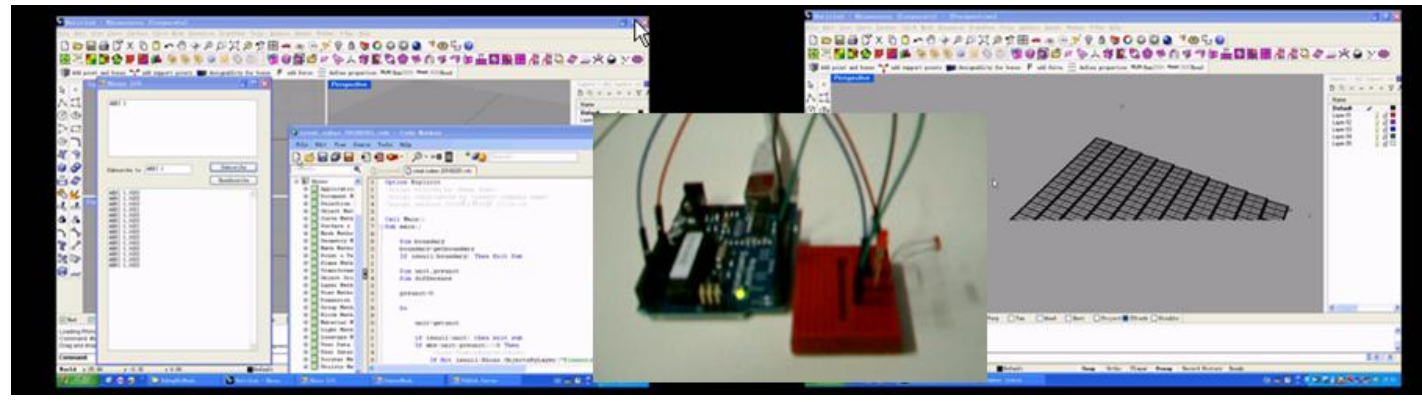

Figure 2. Responsive Rhino 3D models connected to light sensors

Secondly, the student went around a number of popular reading locations around the city of Melbourne and carrying the ambient light informer which consists of an arduino light sensor and a lux reader to measure the ambient light level in these spaces (Figure 3). After general observations and analysing these data, we conclude that on average, Melbournians would find 580-600 lux a comfortable light level for reading. This particular part of the study is essential given there can be cultural differences in how people in general respond to a certain light level in doing specific tasks as 
well as regulatory differences in lighting requirements. This task was also performed to calibrate the arduino light sensor.

Thirdly, we calibrated the reading of the Arduino LDR with the lux reader (Figure 4). Given that the models set up in Rhino can respond to ambient light level read by the LDR, the solution space for the optimal design can be narrowed to those that match the real-time ambient light data.

Finally, he fabricated a number of pavilion models with different scales, colours (to simulate materials), and louver openings (Figure 5). Within the fabricated models on site, he used an Arduino board and three LDRs to measure the ambient light level on site at different times of the summer days to determine the best orientation, material properties, and the angle of louver openings.

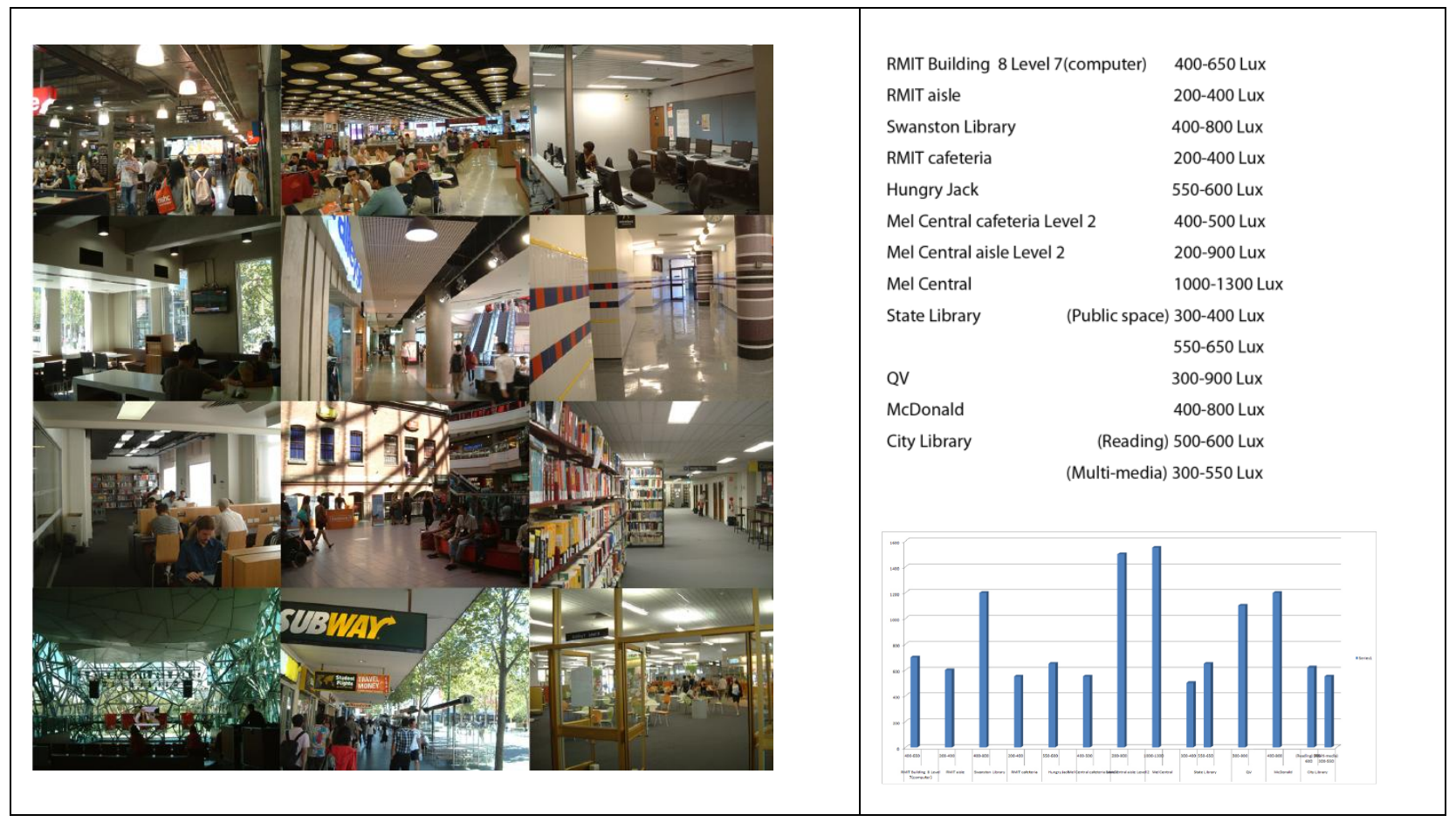

Figure 3. Left-Popular reading locations around Melbourne CBD. Right-the ambient light level measurement.

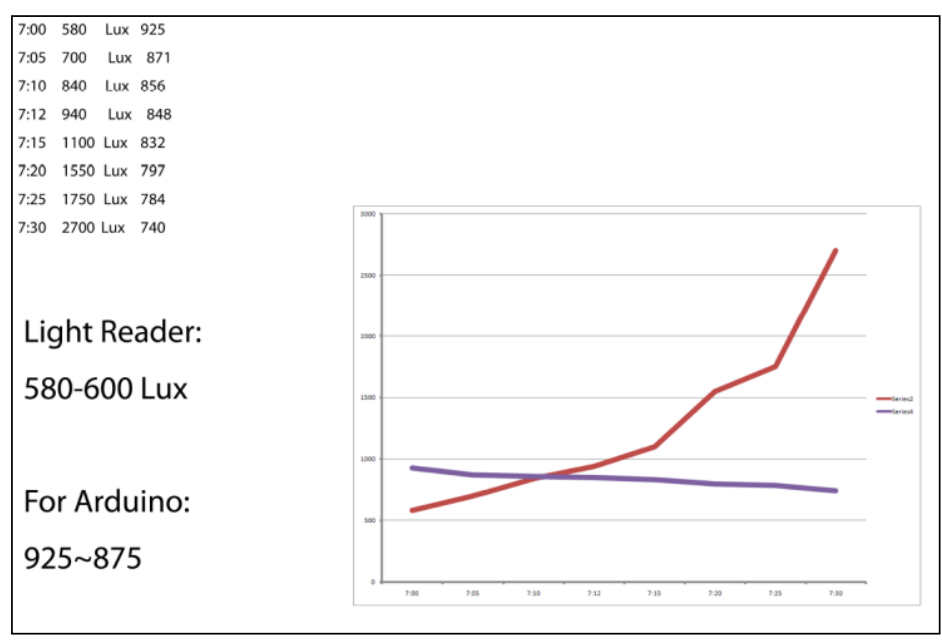

Figure 4. The calibration of the light sensor data and light reader. 


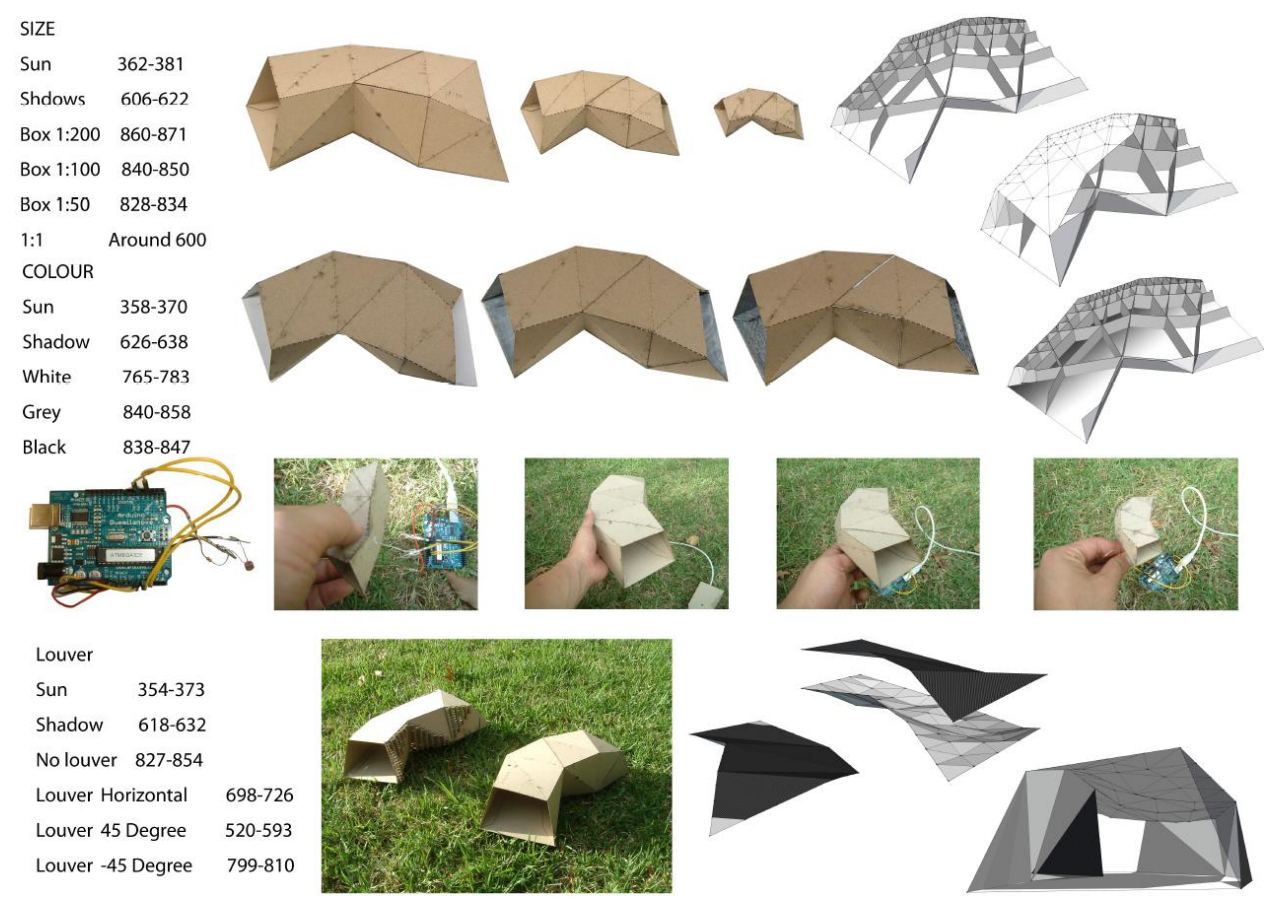

Figure 5. Ambient light analysis using Arduino and light sensors being placed inside the physical models.

This experiment demonstrates the value of working with live / real-time ambient sensor data on site in the modelling process. It also demonstrates the use of embodied virtuality with physical models. The interaction with such physical models becomes embodied since the meaning of the interaction takes place at a certain time, location, and constraints. The manipulation of placement, orientation, size, openings, shadings, and timing of the experiments directly generate data streams that can be further analysed as input to the digital parametric models. Design decisions can be derived from the analysis of the ambient data that are streamed from the digital platform embodied in the physical models.

\subsection{Automated POE}

Architects and urban planners have long used design precedence and energy simulation for designing sustainable built environment. Simulation tools are used to estimate projected energy use and carbon emission during the design stage. However, the actual energy use measured during occupancy stage is often a lot higher than the estimated energy use in the design stage. In order to design buildings that yield high energy ratings and accommodate satisfied occupants, design precedence needs to be coupled with a comprehension of the ambient urban environment and the understanding of occupancy patterns.

The assessment of surveys on workplace conditions, termed as Post Occupancy Evaluation (POE), was conducted in the recently built office tower in Monash University Caulfield campus, using a novel and non-traditional approach. This project was as a two-month summer project in Monash University, conducted by Prateek Rungta.

POE study provides information that can be used either in modifying existing building systems or in subsequent building design to maximize productivity in the workplace by identifying previously successful combinations of variables under a building designer's control. These variables include, but are not limited to, temperature, noise, ambience, space, cleanliness and lighting (Leaman 2004). The 
POE surveys are usually paper based and completed by building occupants, since it is their comfort that the study seeks to evaluate. Naturally, this field is of interest to building managers.

DIY probes can be used to retrieve real-time ambient data and get responses from building occupants. The idea was to replace the traditionally paper based POE surveys with a sensor powered system. A complete solution would be expected to handle most of the POE features (lighting, noise, etc.). Our prototype however, was built around just the temperature variable. Besides a temperature sensor, it used a proximity sensor to detect movement around the device. The probe consisted of an Arduino circuit connected to a computer on which ran a controller program. The circuit components were the temperature sensor, the proximity sensor and two buttons, each accompanied by a feedback LED.

The purpose of this setup was two-fold. First, it measured and reported the current indoor temperature. The controller program running on the computer would read, record and report these temperatures. It would integrate this data with outdoor temperatures, fetched from the web (via the Bureau of Meteorology). The second task performed by the circuit was the automation of the POE. The infra-red proximity sensor would alert the circuit (and the controller) when someone approached the apparatus. The controller would then greet the person, report current indoor and outdoor conditions and ask if they were comfortable inside. The message plays via the computer's audio output. The user can respond by pressing one of the two buttons (labelled 'Yes' and 'No') connected to the Arduino circuit. These responses would also be read and recorded by the controller. Thus the probes automated the survey for temperature related comfort (Figure 1).

Each response was posted online on Twitter and on an RSS feed, using JSON protocol, to inform the building occupants. A web mashup that compares the internal and external temperature of the building and occupants' response was put up. The data collected could be analysed to extract information useful for POE and other stakeholders, such as understanding the patterns and perceptions of occupants' comfort. The early stage of design of an urban public site may use similar installations around the built environments to gather public opinion for a crowdsourced POE from future users.
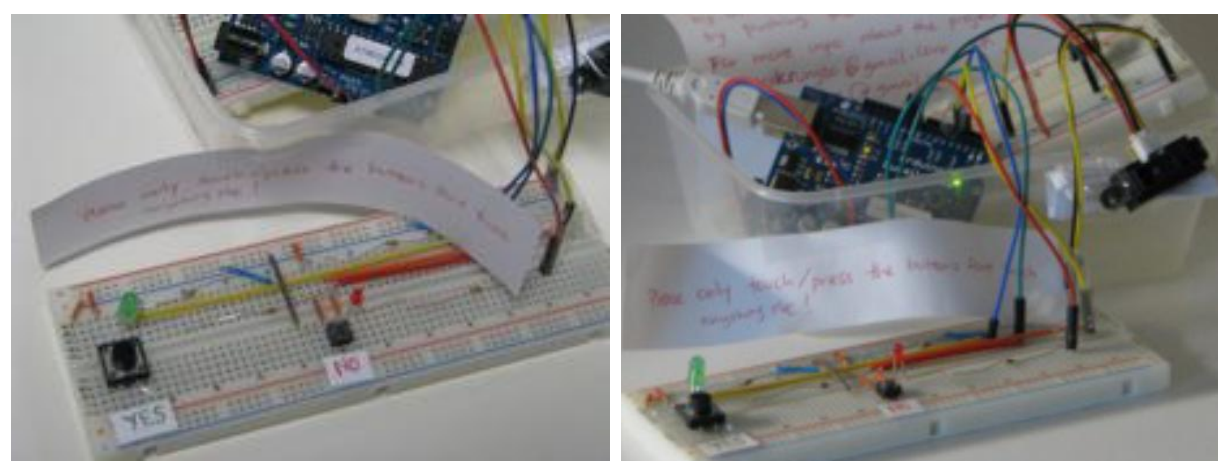

Figure 6. Automated POE physical tool

\subsection{U \& I Aware}

Every minute, on average, no less than one person dies in a crash worldwide (Jones, 2002). The figure of the annual toll of human loss caused by intersection crashes has not significantly changed, regardless of improved road design and more sophisticated Intelligent Transportation Systems (ITS) technology over the years (U. S. Department of Transportation, 2002). Human error is the major contributing factor to road safety risks. There can be various causes of human error, such as lack of situated awareness of the surrounding traffic, traffic blind spot, miscalculation of timing in performing certain manoeuvres, or a deliberate violation to traffic regulation. This can be attributed 
to various road users with different cognitive and physical abilities/disabilities. Thus, behavioural changes need to be advocated through effective information delivery.

Each intersection is unique because of the diversity of intersections' characteristics such as different intersection shapes, number of intersection legs, signalized/ unsignalized, traffic volume, rural / urban setting, types of vehicles using the intersection, various average traffic speed, median width, road turn types, and number of lanes (Salim et al. 2007a). Therefore, the complex nature of intersection collisions requires systems that warn drivers about possible collisions. A meticulous study on a particular intersection by performing site study and observation is usually done to understand different issues in each intersection and perform intervention such as for improving intersection safety.

Our previous work, the U\&I Aware (Salim et al., 2007b) is a context-aware framework for collision avoidance on road intersections. It encapsulated three components: collision learning, collision detection, and collision warning. The framework was designed as the basis of early collision warning device for road users. In particular, the collision learning component employed existing in-vehicle sensors such as Global Positioning System (GPS) and forward, rear, and side collision sensor devices to analyse collision manoeuvres and near-collision events. Since these privately owned probes were not available during the research, the sensor data were simulated. The collision learning component was equipped with data mining techniques to extract collision patterns from data streams from invehicle and on-the-road sensors. By analysing the data from these sensors, we can derive collision patterns of each intersection which are then used to match driver behaviours with the knowledge base to predict future collision. The collision warning system was simulated on mobile devices in each vehicle.

\section{4. iCo2mmunity}

Public transport and personal motor vehicles are major contributors to greenhouse gas emissions and air pollution in urban cities. The City of Melbourne recently issued a publication that presented various strategies to reduce carbon emission to fifty to sixty percents across the municipality by the year 2020 in various areas, of which passenger transport is identified as one of the key areas (City of Melbourne, 2008). In 2003, 73.6\% of total greenhouse emissions in Australia is comprised of CO2, of which $56 \%$ is contributed by the electricity and heat production, while $15.9 \%$ is contributed by public transport and passenger cars (AGO 2003 as cited in Coutts 2006). The major cause of air pollution in Australian urban context is motor vehicles (Australian State of the Environment Committee, 2001) as traffic contributes to $75 \%$ of the total urban air pollution (Simmonds and Keay, 1997). There is a need for a mechanism to quantify the impact made by individuals' choice on their travel modes and leverage the public awareness of the impact of their decision in a positive way.

The City of Melbourne (CBD and surrounding areas) receives 770,000 visitors daily (City of Melbourne, 2009). A major fraction of Melbourne's 770,000 daily visitors are commuters who live outside the city. The city's current residential population is around 90,000 (City of Melbourne, 2009). Melbourne has 1700 new residents each week (Real Estate Institute of Victoria (REIV), 2009) and its population is predicted to grow by 1 million in 2030 (Department of Sustainability and Environment (DSE), 2002). The impending growth of the city places more burdens on the existing transportation infrastructure and road networks that are already heavily under-performing and the impact propagates on specific urban issues, including road safety, carbon emission, occupancy and comforts, and crime and safety.

The increasing travel-time also contributes to the increase of personal carbon footprints of commuters. The increase of CO2 is parallel to population and density increase (Hoffmann, 2009; Coutts, 2006). In the city of Melbourne, the trends of atmospheric pollutants closely follow the 
trends of traffic volumes (Simmonds and Keay, 1997). Although railways accounted for only $2.5 \%$ of 2008 transport emissions, road transport accounted for $86.3 \%$ of 2008 transport emissions, an increase of $27.5 \%$ between 1990 and 2008. This is because $91 \%$ of 770,000 daily commuters to the city of Melbourne work (City of Melbourne, 2009) opting to drive to work (IBM Press Room, 2010).

Clustering of population profiles, based on preferred transport mode, reveals trends that will be useful for government to formulate public policies for improvement of the system and public satisfaction (Salim 2010). Since data for such a study is not available, we need to use an urban probe to gather a large dataset from the public, and web and mobile applications are the best tools for this purpose. However, as previously discussed, to compel users to actively participate in the crowdsourcing activity through the application, there must be a value or benefit they receive from participating. Given the choices of various transportation modes in the city and different route options, commuters need access to an online advisory system that provides real-time information on the current and emerging conditions of the urban transportation networks.

We propose an interactive and visual application that provides travellers and commuters with informed choices for commuting in Melbourne. iCO2mmunity is an online application hosted on mobile devices and the web, designed to provide commuters with comparison shopping and just-intime informed choices for commuting in Melbourne. The interface provides users with personalised travel suggestions based on the priorities, schedules, constraints, location, and personal information of each commuter (Figure 7). Users can personalise the application to suit their priorities and preferences in delivering informed choices.

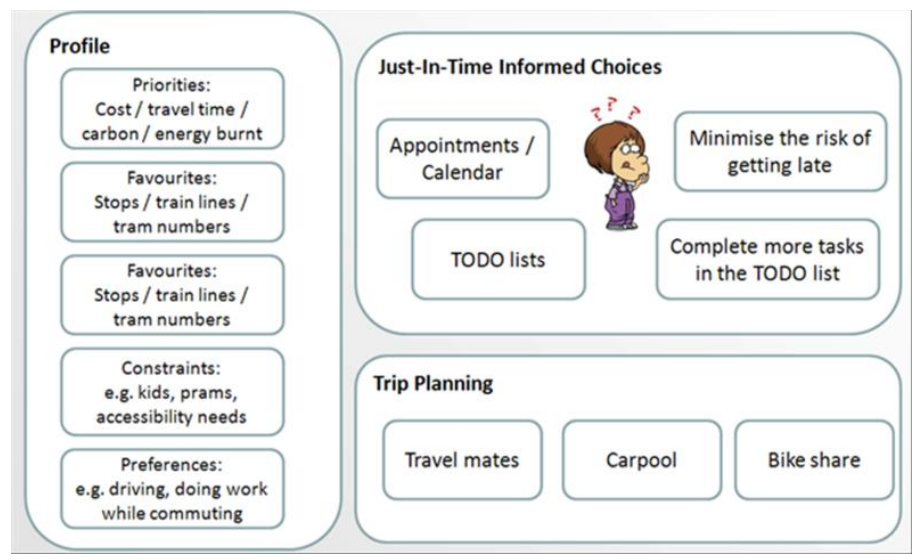

Figure 7. Just-in-time informed choices are delivered based on profile and trip plans

It has an intelligent feature that learns and senses individuals' transportation modes, quantifies their personal carbon footprints, and rewards those who choose greener commuting options. Individuals and organisations can also start green initiatives, such as offering car-pools or bike-share for commuting to work or school, and accumulate reward points (Figure 8). The real-time information about the city and the transportation infrastructure is gathered from the crowd, sensors on the roads and public transports, and the Web. Users can submit their commuting experience and report the conditions of the road, bicycle track, footpath, stations, stops, public transport, wherever they are. The result is a crowd-informed decision making support system for a greener living and a more efficient multimodal transportation.

The persuasion for using the application comes from two key features, the first is the flexibility and usability of the application (Figure 9 and 10), developed by Alhamazani (2010), to inform users based on their profile and preferences, and the second is the ability of getting green rewards for travelling greener. The rewards are termed as carbon credit, which can be used in a carbon trading 
system (Figure 11 and 12) that simulates the idea of selling or buying carbon points through a central system, also developed by Alhamazani (2010), based on real-world Chicago Climate Exchange trading system (http://www.chicagoclimatex.com/).

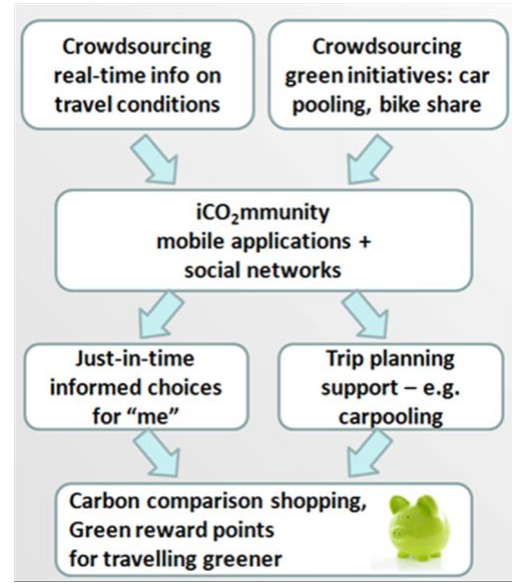

Figure 8 . The data flow process in iCO2mmuity

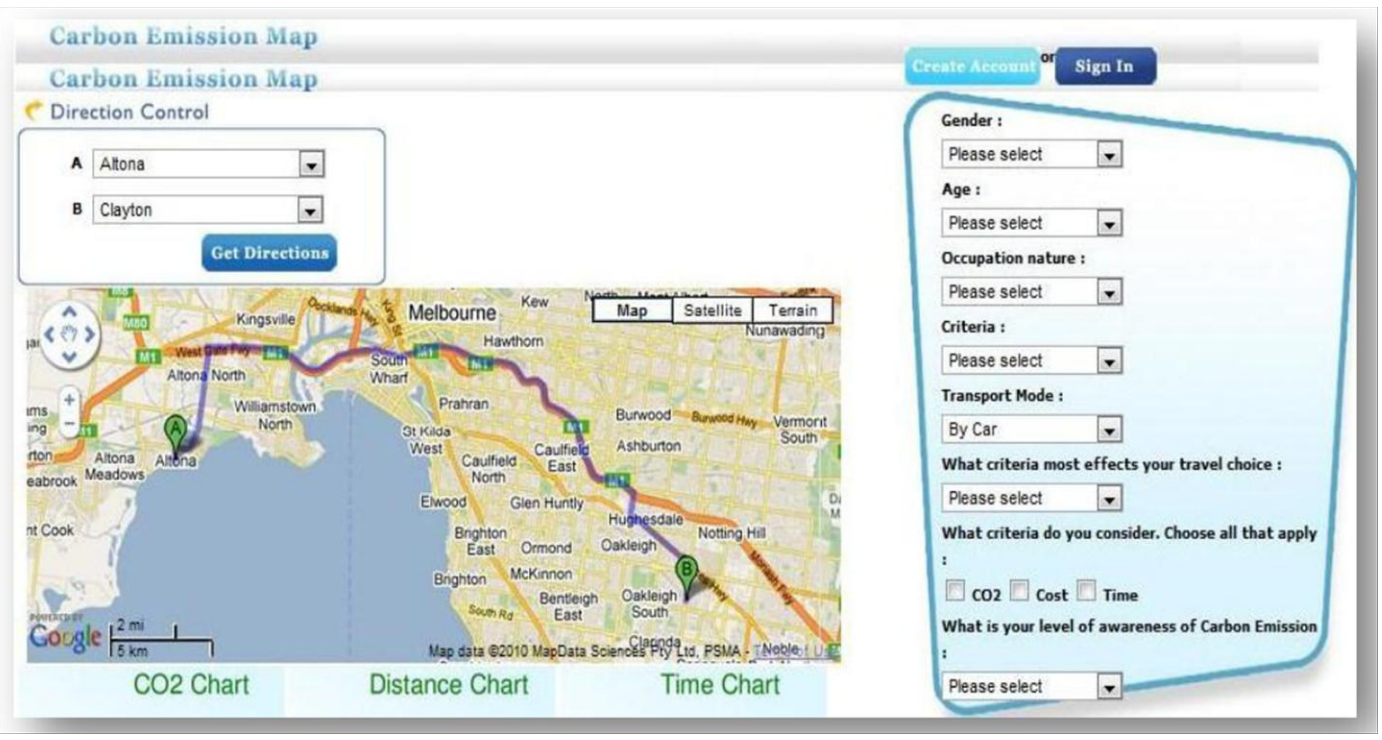

Figure 9. User input to the iCO2mmunity web application 


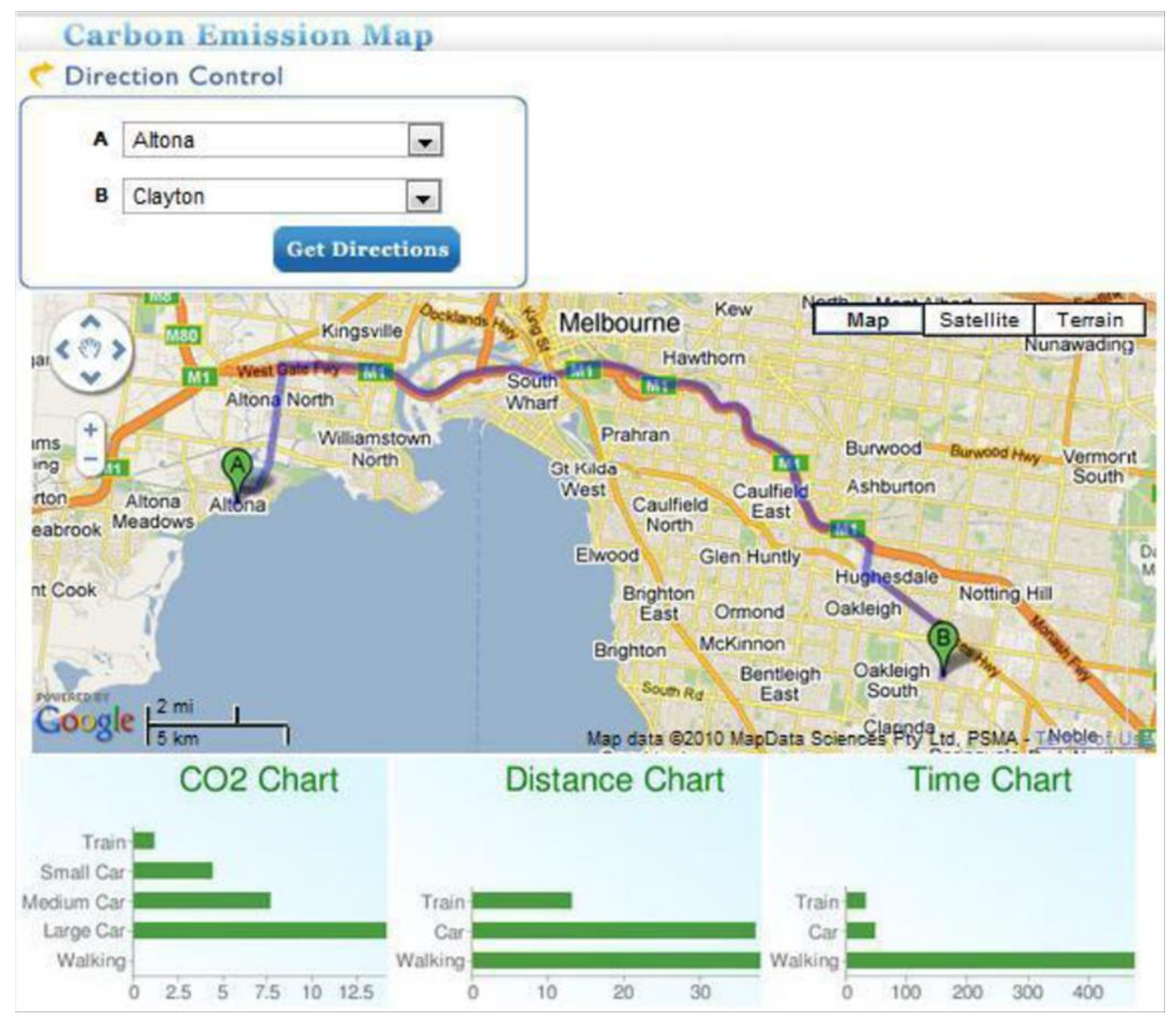

Figure 10. Three charts comparing $\mathrm{CO} 2$, distance and time

As a basic simulation, a friendly and simply designed application to implement a carbon credits trading system to simulate the idea of selling or buying carbon points through a central system. This system has the potential to be linked to the central system we have illustrated in our conceptual model in chapter 3. So that the points gained while travelling can be reflected in this trading system and can be accessible. This method enables users who use their smart cards for travelling to offer the points they have gained within this system. As shown in Figure 6, the application has a page where the user can view his/her carbon credits.

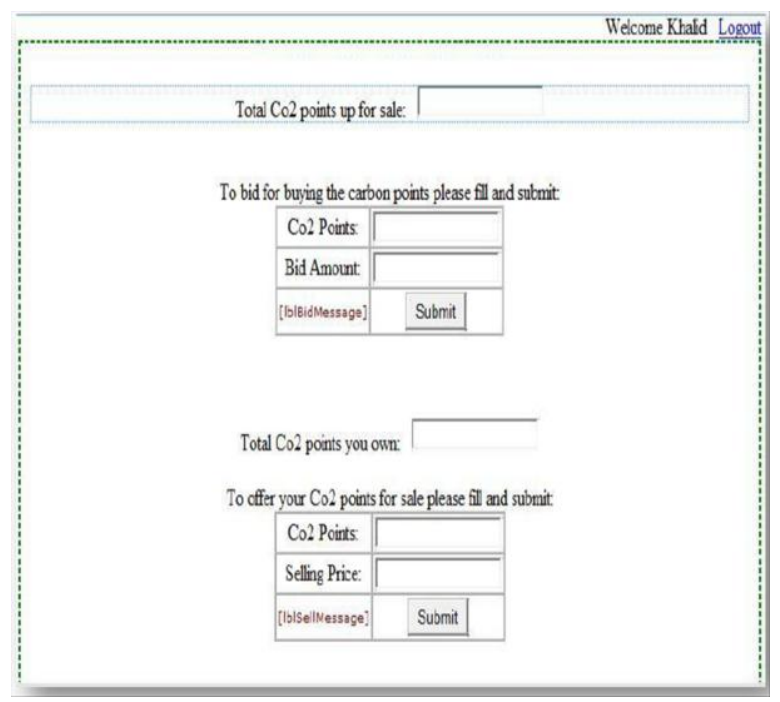


Figure 11 . The main page of the carbon trading system

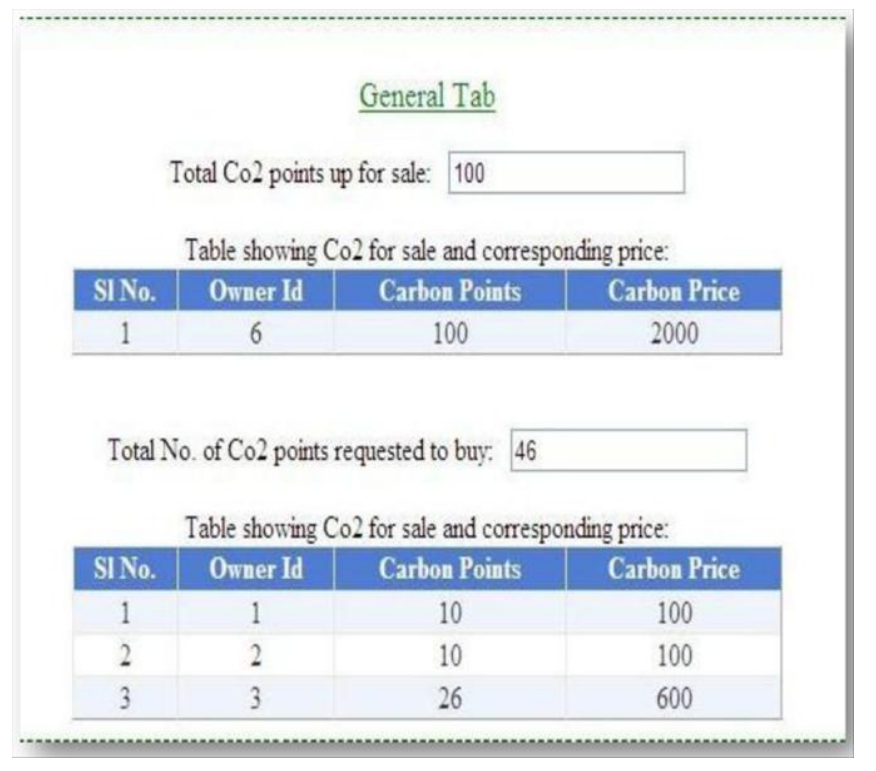

Figure 12. Transaction using carbon points

With the need to increase Melbourne's liveability amidst its growth, iCO2mmunity will help integrating live information sources and optimising the multimodal transportation as a holistic system. Stakeholders and city planners will benefit from information about transportation usage which is being crowdsourced in the system. The integration of live information will also increase usability of information and awareness of greener, sooner, and safer journey planning for travelling across Melbourne. Such information, when analysed and visualised in varying industry domains, can inform strategic decision making in sustainable development of the city. Businesses and services in the city can benefit economically from a more manageable and streamlined transportation system. This project will also help preparing the community for carbon pricing, as there will be an increased awareness of their personal carbon footprints of their daily travelling activities.

\section{5. Transafe}

Local media sources often report that a high percentage of commuters feel unsafe and vulnerable, particularly while travelling on public transportation networks (Herald Sun 2010; The Age 2010a; The Age 2010b). In actuality, however, Melbourne has a very safe transport system and the level of crime occurring on Melbourne's transportation networks is dropping: in 2005-06, 45 offences per million train passengers were reported, compared to 33 per million passengers in 2008-09, where $75 \%$ of public transport offences in the City of Melbourne occur on trains, train stations and station car parks (Victorian Auditor General 2010). In contrast, the safety perception scores on Melbourne's trains is significantly lower than trams and buses, and has not improved over the last five years despite a statistical decrease in the number of offences occurring per passenger (Victorian Auditor General 2010). The perception of safety is important as it influences how people feel and behave towards their surroundings; however, perceptions of safety do not solely depend on levels of crime. Thus, the perception of high levels of crime on Melbourne's public transport can potentially introduce social barriers experienced by (tourist) visitors to Melbourne, international students, and locals who feel unsafe on public transport. Thus, understanding public perceptions of safety and developing policies and strategies to alleviate negative perceptions of crime and safety in the City of Melbourne have become key agendas of Melbourne City Council and Victorian State Government.

With all these complex sustainability, performance, and safety issues of public transportation, we need to gather public opinion and sentiments about Melbourne's transportation network. We use 
mobile devices as probes to crowdsource data from public. The challenge of using mobile applications as probes to crowdsource information is that applications must be useful, attractive, and persuasive that users will be compelled to actively contribute information. Fogg stated that a computer application can play the role as a persuasive social actor by rewarding the users with constructive feedback, simulating targeted user behaviour, or giving social support (Fogg 2002). The rapid advancement of Web 2.0 technologies has pushed the edge for online persuasion, given the ability of social marketers to "outreach" to larger online social players (Chinn and Artz 2008).

When mobile phones are loaded with applications that enable crowdsourced content to be submitted, the applications would evolve over time with developers only need to create an intuitive placeholder for the crowdsourced content. We call this as crowd place-making, spatial movement of the crowd that is voluntarily reported via mobile applications that can track their locations using GPS and geotagging and accept rich user inputs about their whereabouts. Foursquare have become a popular social-networked place-making application and has been used widely given that the app for Blackberry and iPhone are available and it is connected to Facebook's status updates. Users of foursquare can "check-in" to places in the city, "shout" their status, and share tips about a place. If a place does not yet exist in the app, users can create new place, add information about the place, and add it to existing categories (i.e. restaurant, entertainment, education, transportation infrastructure, shopping, and so on). This type of applications is reliant on the crowd to populate the content and hence the existing application is capable of evolving from one use to another. Foursquare has also been used by shop and restaurant owners to promote their business by adding incentives and vouchers to those who are using foursquare to "check-in" into their locations. Hence, the application has evolved from a purely place-making tool to a marketing tool. Facebook has followed suit when Facebook Places was introduced.

Transafe combines interactive mobile applications with social media to capture and analyze public perceptions of safety to deliver 'crowdsourced' collective intelligence about places in the City of Melbourne and their affective states at various times of the day (Hamilton et al. 2011). In contrast to a related precedent, Oakland Crimespotting, which is a project that mashes up crime data from local police authority and visualize it in Google Map, Transafe gathers the locals' perception of crime and safety and compare it with data from local police and Crime Stoppers. Figure 13 illustrates the proposed platform for Transafe, centered around a mobile phone application that allows for:

- Direct user interaction: users interact with the application to submit and view crowdsourced crime and safety perception data. Mobile phone sensors will be used as input for user placemarking, timestamps etc.

- Stakeholder interaction: organizations such as city councils, public transport entities, and state government can input infrastructure or (real-time) transport information and law enforcement can provide crime news and information;

- User services: improving personal safety perceptions through enabling a user tracking system, or connection to civil services such as emergency calls ('000') or criminal/suspicious activity reporting to Crime Stoppers. 


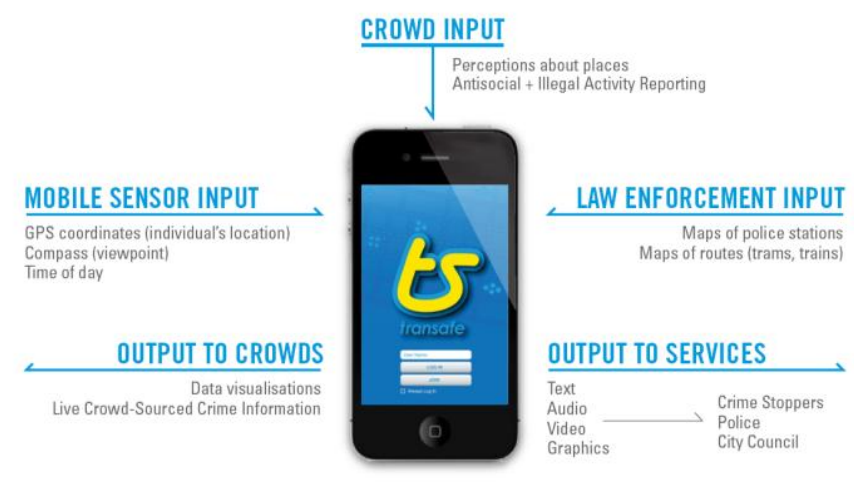

Figure 13. Proposed Transafe platform

As an urban probe, Transafe introduces the use of an 'emometer', a crowd voting mechanism with emoticons to encourage people to explain their feelings or perceptions of a particular place at any given time. These emoticons have ranges of intensity and so the user can provide an intricate color display of perceptions. A user can enter information about their perceptions of a particular area by selecting one or all of the 8 emoticons with different colors representing Sad/Happy, Bored/Excited, Scared/Safe, Angry/Peaceful sliding scales (see Figure 14).

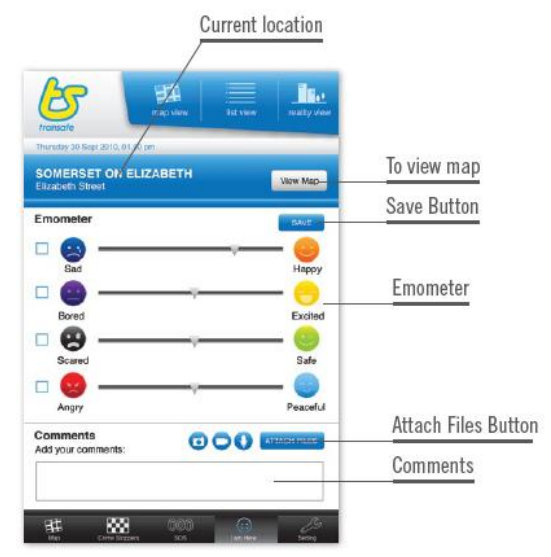

Figure 14. Emometer

The submitted Emometer data is then aggregated across the user crowd and the result will determine the overall color/mood of a particular area/locale. Visualizing the 'feelings' of places in the city on different 'map', 'list' and 'reality' viewing modes then allows for the user to see collective safety perceptions of places at different granularity (see Figure 15): Figure 15a illustrates the 'map' view augmented with the crowd's 'mood' for each city block; Figure 15b shows the 'list' view of the crowd's mood for particular buildings and landmarks; and, Figure 15c depicts the 'reality' map indicating nearby buildings and facilities. 


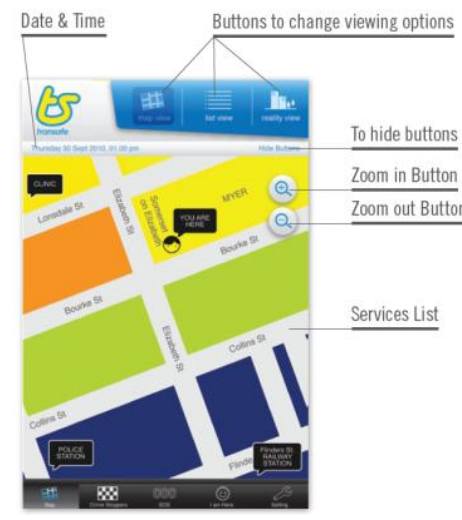

(a) Map view

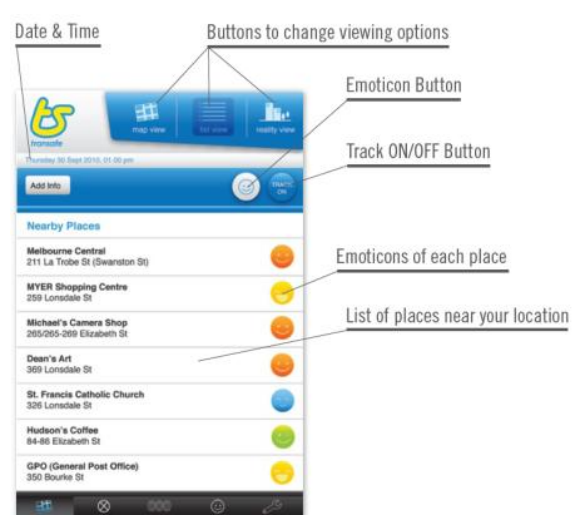

(b) List view

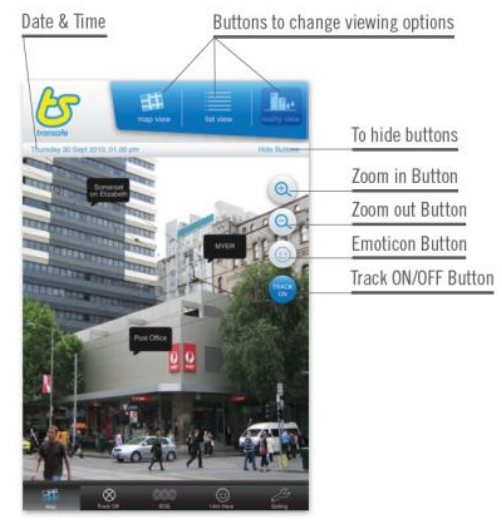

(c) Reality view

Figure 15. Multiple map view interface

Once the Transafe application has been fully developed, we will need to extensively test and evaluate it on a variety of users. We will need to enable recognition of the individual user contributions through the emoticons and uploading of information. We need to explore the effective ways to influence users to submit information to Transafe and hence build up the collective intelligence about the city. Transafe needs to be designed to encourage users to keep the application running and submit information to the Transafe crowdsourced database.

In the Transafe platform and mobile phone application presented in this paper, crowdsourced social network data can be clustered and labeled to discover patterns of public sentiments over a specific place in the City of Melbourne at different times of the day. Finding recurring patterns and monitoring emergence and changes of the sentiment patterns can inform us of specific activities, events, time, or places that affect public perception of safety. By applying association rules mining, we can thus discover public perception trends in relation to various factors and user groups of the city. Such information can then be streamed back to the public or stakeholders of the city and better inform city planning.

\section{Conclusion}

We have proposed ambient and community sensing as a method for surveying the city for specific environmental, behavioral, or cultural investigations. Sensor devices can be used as urban probes to gather data that can be analyzed for urban intervention or informing design decision making processes in an urban project. The use of urban probes is instrumental for understanding a specific urban context. Types of urban probes include existing sensors embedded in the natural or built environment, in urban infrastructure and vehicles, mobile devices, and Do-It-Yourself (DIY) sensing devices. We have showcased five projects that employed ambient or community sensing prototypes as probes for a specific urban context. Future works include a tighter integration between ambient and community sensing by linking physical computing and mobile devices as probes and correlating data gathered from the integrated probes. The integration will provide a powerful combination of the extensibility, creativity, and customizability of DIY physical computing prototypes and the mobility, connectivity, and social aspects of mobile devices.

\section{References}

K. T. Ahalmazani, Pervasive Awareness and Persuasive Technology for Sustainable Travel Behaviour, $\mathrm{PhD}$ Thesis, (Melbourne, Australia: Caulfield School of Information Technology, Faculty of Information Technology, Monash University, 2008).

Arduino, <www.arduino.cc $>$ Accessed Feb 24, 2012. 
Australian Greenhouse Office (AGO), Overview: 2003 Australian national greenhouse gas inventory, Department of Environment and Heritage, Canberra.

Australian State of the Environment Committee, Australia State of the Environment 2001, Independent Report to the Commonwealth Minister for the Environment and Heritage. (Canberra: CSIRO Publishing on behalf of the Department of the Environment and Heritage, 2001) <http://www.environment.gov.au/soe/2001/publications/report/pubs/soe2001.pdf > Accessed Feb 24, 2012.

City of Melbourne, Zero Net Emissions by 2020 Update 2008. (Melbourne: Melbourne City Council, 2008) $<$ http://www.melbourne.vic.gov.au/Environment/WhatCouncilisDoing/Documents/zero_net_emissions_2020. pdf $>$ Accessed Feb 24, 2012.

City of Melbourne, City of Melbourne Annual Report 2008-09 (Melbourne: Melbourne City Council, 2009) http://www.melbourne.vic.gov.au/annualreport/ourcity_melbtoday.shtml Accessed Feb 24, 2012.

S. J. Chinn and N. Artz, "Social Marketing, Social Networking," in R. A. Oglesby and M. G. Adams, ed., Business Research Yearbook: Global Business Perspectives. Vol. 15, (Beltsville, MD, US: International Academy of Business Disciplines, 2008) 395-400.

A. M. Coutts, J. Beringer, and N. J. Tapper, "Characteristics influencing the variability of urban CO2 fluxes in Melbourne, Australia", Atmospheric Environment, Vol. 41, January (2007) 51-62.

P. Dourish, Where the Action Is: The Foundations of Embodied Interaction, (Cambridge: MIT Press, 2001).

N. Eagle, A. Pentland, and D. Lazer, "Inferring Social Network Structure using Mobile Phone Data", Proceedings of the National Academy of Sciences (PNAS), 106(36), (2009) 15274-15278. <http://reality.media.mit.edu/pdfs/Eagle PNAS09.pdf>

B. J. Fogg, Persuasive Technology: Using Computers to Change What We Think and Do (Interactive Technologies) (San Francisco: Morgan Kauffman, 2002).

B. Gaver, T. Dunne, and E. Pacenti, “Design: Cultural probes”, Interactions, Vol. 6, 1, January (1999) 21-29.

M. Hamilton, F. Salim, E. Cheng, S.L. Choy, "Transafe: A Crowdsourced Mobile Platform for Crime and Safety Perception Management", paper presented at ISTAS 2011: IEEE International Symposium on Technology and Society, (Chicago, May 23-25 2011).

Herald Sun (2010), "Government says rail crime rate dropping as violence hotspots revealed", Herald Sun (June 28 2010) <http://www.heraldsun.com.au/news/victoria/citys-most-dangerous-stations/story-e6frf7kx1225884963316> Accessed Feb 24, 2012.

G. Hertz, “Arduino Microcontrollers and The Queen's Hamlet: Utilitarian and Hedonized DIY Practices in Contemporary Electronic Culture", Proceedings of the 31st Conference of the Association for Computer Aided Design in Architecture (ACADIA 2011), (Banff, Canada, 11-16 October 2011), 44-47.

IBM Press Room, "IBM Global Commuter Pain Study reveals Melbourne drivers have one of the best commutes in the world" (01 July 2010) 〈http://www-03.ibm.com/press/au/en/pressrelease/32029.wss> Accessed Feb 24, 2012.

A. Jhingran, "Enterprise information mashups: integrating information, simply", Proceedings of the 32nd international conference on Very Large Data Bases (Seoul, Korea: VLDB Endowment, 2006) 3-4.

W. D. Jones, "Building safer cars", IEEE Spectrum, vol. 39 (2002) 82-85.

A. Krause , E. Horvitz , A. Kansal , F. Zhao, "Toward Community Sensing", Proceedings of the 7th international conference on Information processing in sensor networks, (April 22-24 2008), 481-492.

A. Leaman, "Outside the comfort zone: building human and basic needs", Human Gives Journal, Vol.11, No. 2 (2004).

I. Mergel, "Gov 2.0 revisited: Social media strategies in the public sector", PA TIMES, 33(3) (Summer 2010), 7, 10. <http://patimes.eznuz.com/printFriendlyPDF/articlePDF/22647.pdf> Accessed Feb 24, 2012.

Oakland Crimespotting <http://oakland.crimespotting.org> Accessed Feb 24, 2012.

Open Street Map <http://openstreetmap.org/> Accessed Feb 24, 2012.

Pachube, <www.pachube.com> Accessed Feb 24, 2012.

Pachube, "Crowdsourced real-time radiation monitoring in Japan" (March 24, 2011) <http://community.pachube.com/node/611\#3d > Accessed Feb 24, 2012. 
E. Paulos and T. Jenkins, "Urban probes: encountering our emerging urban atmospheres", Proceedings of the SIGCHI conference on Human factors in computing systems (CHI) (2005).

C. Ratti and D. Berry, in V. Chatelet ed. "Sense of the city: wireless and the emergence of real-time urban systems". Interactive Cities, Editions HYX, (Orléans: 2007).

F. D. Salim, S.W. Loke, A. Rakotonirainy, B. Srinivasan, S. Krishnaswamy (2007a), "Collision pattern modelling and real-time collision detection at road intersections", Proceedings of the 2007 IEEE Intelligent Transportation Systems Conference, (Seattle, USA, 30 September - 3 October 2007).

F. D. Salim, S.W. Loke, A. Rakotonirainy, B. Srinivasan, S. Krishnaswamy (2007b), "U\&I aware: A framework using data mining and collision detection to increase awareness for intersection users", The 21st International Conference on Advanced Information Networking and Applications Workshops, (Niagara Falls, Canada, 21-23 May 2007), 530-535.

F. D. Salim, L. Cai, M. Indrawan, S.W. Loke, "Road intersections as pervasive computing environments: towards a multiagent real-time collision warning system", Proceedings of the Sixth Annual IEEE International Conference on Pervasive Computing and Communications (PerCom 2008), (US: IEEE, 2008)

F. D. Salim, J. Burry, J., D. Taniar, V.C. Lee, A. Burrow, "The Digital Emerging and Converging Bits of Urbanism", Proceedings of eCAADe 28th conference: Future Cities, (Zurich, Switzerland, 15-18 September 2010).

F. D. Salim, H. Mulder, J. Burry, "Form fostering: A novel design approach for interacting with parametric models in the embodied virtuality", Journal of Information Technology in Construction (ITcon), vol. 16, (2011) 133-148.

Y. Santo, J. H. Frazer, R. Drogemuller, "Co-adaptive environments: investigation into computer and network enhanced adaptable, sustainable and participatory environments", Proceedings of eCAADe 28th conference: Future Cities, (Zurich, Switzerland, 15-18 September 2010).

I. Simmonds, K. Keay, "Weekly cycle of meteorological variations in Melbourne and the role of pollution and anthropogenic heat release", Atmospheric Environment, 31, (1997) 1589-1603.

The Age (2010a), "Tram violence taskforce dissolved," The Age (June 9 2010) <http://www.theage.com.au/victoria/tram-violence-taskforce-dissolved-20100608-xtog.html $>$ Accessed Feb $24,2012$.

The Age (2010b), "It's a war zone, say Melbourne's train drivers," The Age (June 12 2010) <http://www.theage.com.au/victoria/its-a-war-zone-say-melbournes-train-drivers-20100611-y3o7.html> Accessed Feb 24, 2012.

U.S. Department of Transportation - Federal Highway Administration and Institute of Transportation Engineers (2004), Intersection Safety Briefing Sheet, 〈http://www.ite.org/decade/pubs/BriefingSheets.pdf>, Accessed Feb 24, 2012.

Victorian Auditor General, "Victorian Auditor General's Report: Personal Safety and Security on the Metropolitan Train System," (Victorian Auditor General's Report, June 2010). <http://download.audit.vic.gov.au/files/20100609_Rail_Safety_Full_Report.pdf> Accessed Feb 24, 2012. 